\title{
Study on Urban Catchment Delineation Based on Improved RIDEM
}

\author{
Ya Ban ${ }^{1+}$, Haiyan Sun ${ }^{1}$, Taili Wan ${ }^{1}$, Lan Ma ${ }^{1}$ and Hongying Liu ${ }^{2}$ \\ ${ }^{1}$ School of Geodesy and Geomatics, Wuhan University, Wuhan, Hubei, 430079, P.R. China \\ ${ }^{2}$ Jiulongpo District, Chongqing Administration of Work Safety, Chongqing, 400050, P.R. China
}

\begin{abstract}
The catchment delineation from DEM is a prerequisite for calculation of urban rainfall runoff and con-centration. Direct delineation watersheds from traditional method in urban result in significant departures from reality. An improved watershed algorithm based on Rural Infrastructure Digital Elevation Model was proposed, for the problems traditional methods encountered. This method took rainwater grates and drainage pipes as inlets to delineate watersheds by integrating factors (i.e. roads, buildings and rivers) which affected rainfall runoff into DEM, and a case study was carried out in a selected area of Kunming. The predicted time series match well with the monitored, which can provide more reliable predictions for Storm Water Management Model (SWMM). The results prove that the result accuracy is better than existing methods. The results can provide valuable reference for planning, design and optimized analysis of rainwater pipe network.
\end{abstract}

Keywords: digital elevation model, rain grate, catchments basin, rural infrastructure digital elevation model, storm water management modle1.

\section{Introduction}

A catchment area is a hydrological unit where precipitations that fall into this area. The raster-based algorithms, which usually use DEM in their approach, are very common in automated catchment area delineation [1]-[7]. D8 algorithm is commonly used to extract catchment areas based on DEM [8,9]. However, error (such as parallel drainages) often occurred when direction of runoff and hydrological information are directly extracted by D8 algorithm in the plain area such in urban areas. This leads to great difference between extracted catchment boundaries and the reality [10], [11]. Many scholars at home and abroad have carried out research and improvement to this problem, and propose multiple flow direction algorithm, Burn in algorithm and DRLN algorithm [12], [13]. These improved algorithms and models have better applicability in the plain areas with less influence of human activities and they improve the accuracy of catchment areas. However, in the plain area of rapid urbanization, these improved algorithms and models cannot obtain satisfactory catchment boundaries. In addition to plain terrain, human activities (road construction, density buildings, drainage ditches, etc.) will influence boundary of catchment path and catchment area [14], [15].

However, the deficiency of many hydrological and water quality models is their inability to account for the effects of terrain on flow processes. Linear landscape feature (tillage, roads, ditches, and rivers) can significantly affect the hydrological geomorphological processes within a watershed. However, mostly hydrological models continue to rely solely on regional digital models to derive overland flow directions even through DEM. Duke [14] introduces a methodology that improves the accuracy of grid-based overland flow routing through the use of ancillary roads, ditch, and culvert data.

Moreover, human activities (i.e. roads and streams, buildings, some ponds and pipe systems) also can significantly affect the hydrological geomorphological processes in urban. In this paper, to downscale the

+ Corresponding author. Tel.: + 8613554535239; fax: +027-87160925.

E-mail address: banya@whu.edu.cn. 
DEM and extract drainage structures and watershed boundaries with improved accuracy a new method is proposed based on the rural infrastructure DEM is able to incorporate ancillary data and take into consideration of anthropogenic land cover features (i.e. roads and streams, buildings, rainwater grates and pipe systems) that influence drainage patterns.

\section{Catchment Division Algorithms}

Urban drainage network system mainly has two components: the drainage pipe and pipe nodes such as rain grates, manholes, outlets and pumping stations. Drainage network consists of rain grate, inspection well, water outlet and rainwater pipes (shown as Fig.1). After the process of surface run-off, rainwater flows into the drainage system through grates and finally into rivers and lakes. The surface area whose rainwater flows into the same grate is this grate's corresponding catchment.

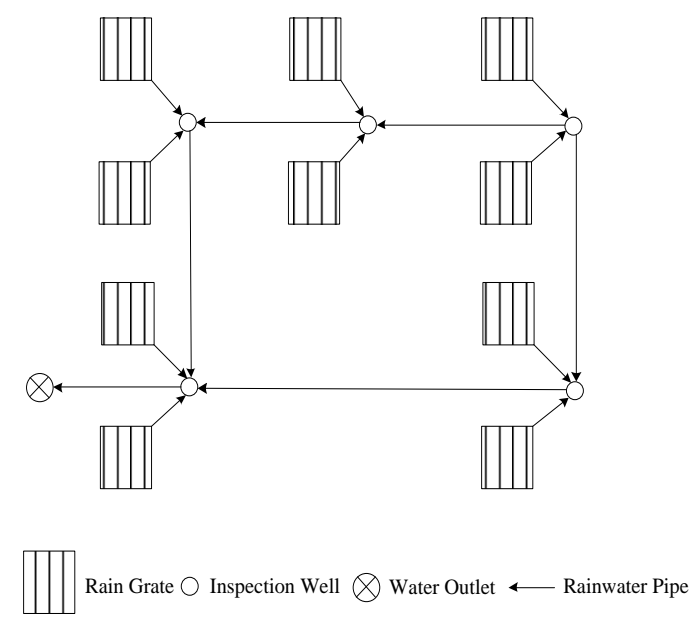

Fig. 1: Drainage network.

Terrain feature shows the surface height variation and therefore is usually regarded as the most important factor that determines the hydrologic analysis result. Regular-grid DEM, as a digital simulation mean of terrain feature, is always utilized to extract catchment information.

However, DEM only represents elevation information of urban surface. Different types of land use/land coverage can have big influence on the analysis of flow direction and accumulation route. For example, flow route may be blocked by buildings and change direction accordingly. Another case is that buildings are likely to be equipped with vertical drains, from which rain that falls on the roof will drain off.

As for urban region with sophisticated drainage network, the catchment division relies on not only the elevation and land use type, but also the location of Inlets. Inlets such as rain grates and vertical drains will impact run-off direction. Thus, by splitting and weakening stream, inlets change the run-off path and catchment area.

The main idea of this algorithm is to overlay DEM with features, such as roads, lakes and buildings, which influence run-off direction and flow route. Thus the integrated DEM can reflect a more accurate terrain. Subsequently the operation of filling DEM depression is executed. Considering grates and vertical drains as catchment inlets, we find out all the raster cells corresponding to every catchment inlet with the breadth-first search algorithm. Catchments are finally divided according to different raster cell areas.

Before catchment division, the land use type data and urban drainage network data should be processed. The original vector-formatted land use data, which displays in polygons, is converted to raster data that has the same coordinates and resolution with DEM for a better use. After converting we get a raster matrix, which stores land use type code. Information of grates and vertical drains are given with geographical coordinate format, which should be converted and calculated into row and column numbers obedient to DEM:

$$
\begin{aligned}
& R=[(x-x \text { corner } / d)] \\
& L=[(y-y \text { corner } / d)]
\end{aligned}
$$


where, $R$ as the raster of row number; $L$ as the raster of column number; $x$ as the inlet coordinate of $X ; y$ as the inlet coordinate of Y;xcorner as the lower-left corner coordinate of $X ; y$ corner as the lower-left corner coordinate of $Y ; d$ as DEM resolution or cell length;[] as the rounded calculation.

The algorithm of calculating grate catchment can be summarized as following (in Fig.2):

(1) Grates are successively numbered and stored in a list. Then a queue (marked as $A$ ) is created to store catchment borders and a two-dimension array (marked as $B$ ), which has the same row and column numbers with DEM, is created with -1 as default value to record whether DEM cell has been divided.

(2) Subsequently, a grate is selected as seed point and stored in queue $A$. The grate number is set as value of the grate's corresponding cell in array $B$.

(3)Seed point is picked and excluded from queue $A$. Then the values in array $B$ of the seed's eight neighbourhood cells are judged in turn. If the value doesn't equal to -1 , which means that this cell has already belonged to another catchment, the process will move on to the next neighbourhood cell. If the value equals to -1 , which means that this cell belongs to no catchment yet, further judgment based on land use type is carried: if the land use type of the raster is a river or building one, the process will move on to the next neighbourhood cell; otherwise, the flow direction of the cell is calculated to see whether pointing to the seed. If true, the cell is added into queue $A$ and value of this cell in array $B$ is set equal to the grate number, indicating this cell belongs to catchment of the grate (also seed point).

(4)After the eight neighbourhood process, every point stored in queue $A$ is picked as seed point successively and step (3) is executed. The iteration of catchment corresponding to one grate is finished when there are no points in queue $A$. The catchment result is displayed in array $B$ with cells which have the same value with grate number.

(5)Iteration of calculating catchment area for each grate is carried out by repeating step (1)-(4). Array $B$ stores the catchment division result, in which catchments corresponding to grates are identified by cells values.

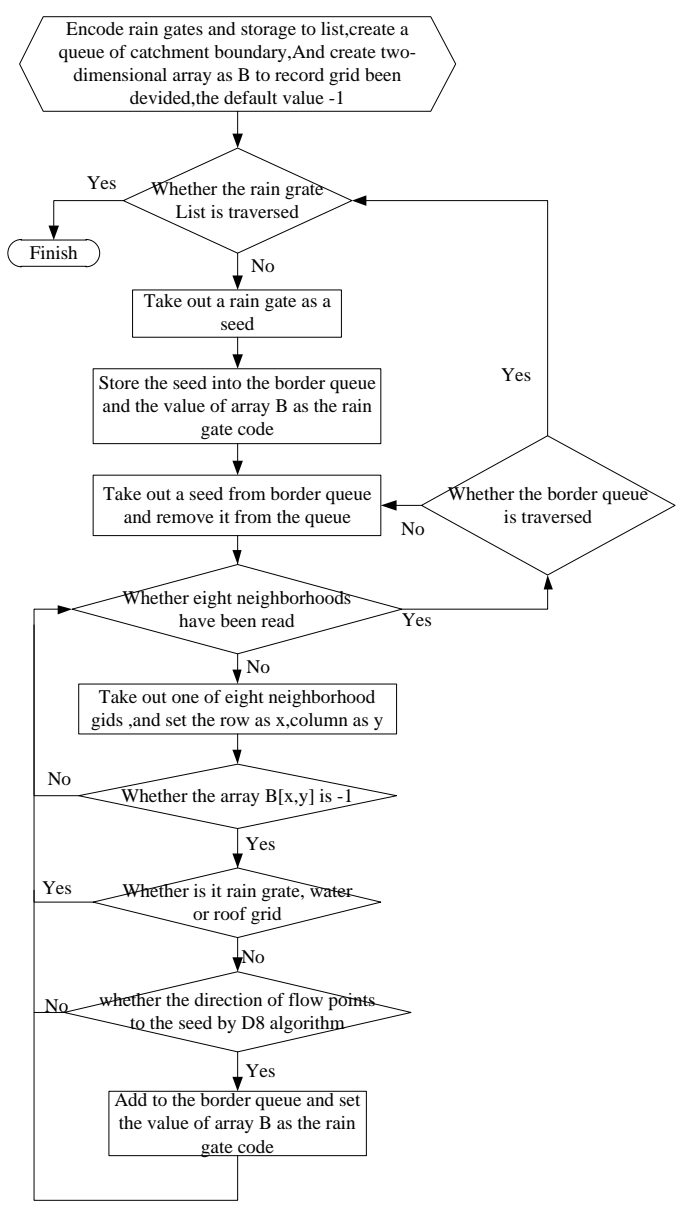

Fig. 2: Flow chart of rain grate catchment delineation. 
The catchment division algorithm of vertical drains is basically the same with that of grates. The only difference lies in step (3) when judging the values of eight neighbourhood cells: if the cell is a building-roof type and value in array $B$ doesn't equal to -1 , which means the cell has already belonged to another catchment, the process will move on to the next neighbourhood cell; if the cell is a building-roof type and value in array $B$ equals to -1 , which means that this cell belongs to no catchment yet, the cell will be added into queue $A$ and value of this cell in array $B$ is set equal to the vertical drain number. The catchment division result in array $B$ is identified with different vertical drain values.

After the two processes mentioned above, the ground raster and roof raster with vertical drains have been aggregated into catchments, leaving roof raster without vertical drains to be further dealt with.

Rainwater that falls on the roof without vertical drains will gather on the roof, flow onto the ground and finally into grates or rivers and lakes. The roof raster with the case of flowing into grates should be updated into corresponding grate catchment:

(1)Traverse array $B$ and find out cells with value of -1 , which means they haven't been divided into any catchment yet. For each cell, the elevation value is obtained based on DEM data to judge whether it is a roof type or not. If being a roof type, the cell is regarded as the beginning point to find out the whole roof area with seed diffusion method.

(2)Search for the border raster that contains the roof area. When the roof area stretches across more than one catchment, it is allocated to the catchment containing the majority cells.

The catchment division is here to complete. The result is stored in array $B$ and catchments are represented by different cell values.

\section{Experiment and Analysis}

In order to verify the accuracy and practicability the new algorithm proposed in this paper, C\# programming and ArcGIS Engine are used. Take the case of an artificial village in Kunming, as an example, experimental data including DEM, land use types and the drainage pipe network data. This study area covers 12.43 square kilometers, with an average slope of $2.93 \%, 36.20 \%$ building area, $11.12 \%$ green area, $43.93 \%$ roads, $0.56 \%$ rivers system, and the rest $8.18 \%$ is other land use. The impervious area is about $80.13 \%$, and the population is about $3.2 \times 104$.

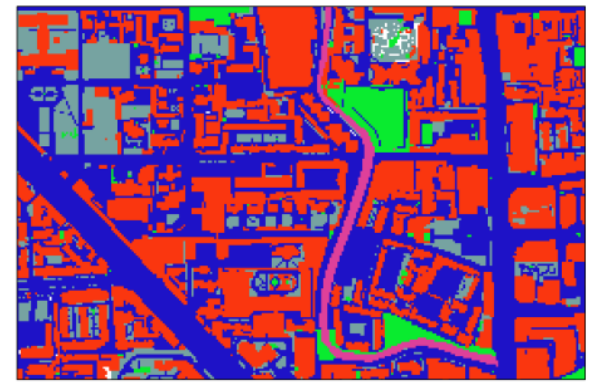

(a)

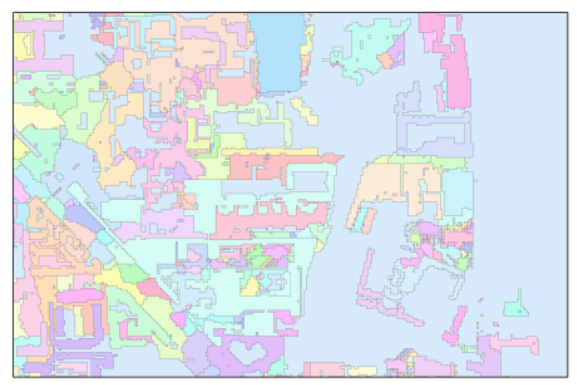

(b)

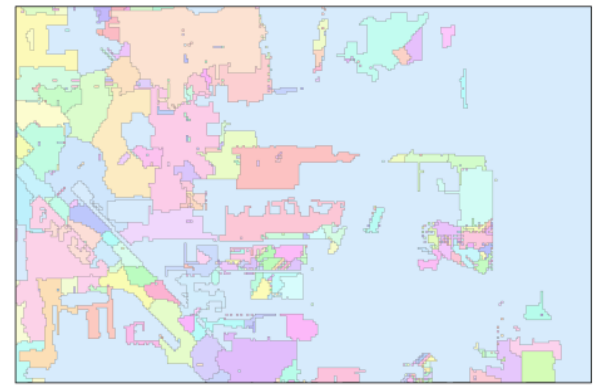

(b)

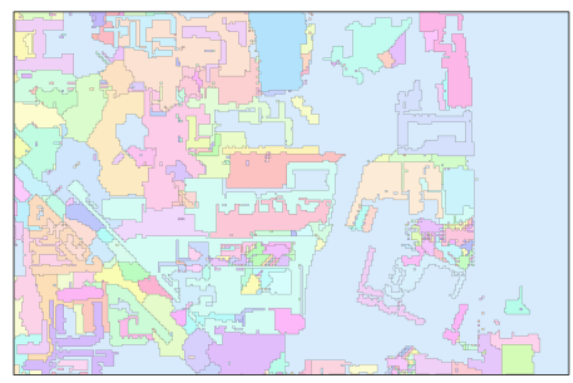

(d)

Fig. 3: Catchment delineation during the different refined processes:(a) Vegetation distribution;(b) Considering the effect of pipes ;(c) Considering the effect of buildings and pipes;(d) Final results. 


\subsection{The experimental results and discussion}

As shown in Fig.3, the results of catchment delineation during the different phase by overlaying and dissolving different impact factors are given. Fig.3(a) shows the dispersion of vegetation of this study area, which includes greenbelts, roads, buildings, drainage pipes system, etc. In Fig.3(b), (c) and (d), the continuous different color is the catchment area, and each catchment area contains a rain grate or drainage pipe. There is a one-to-one match between catchment and rain gate or drainage pipe, which means the rain falling in this area will gather in this region. The rain flows to the rivers and lakes may participate in the catchment delineation, which can be avoided by overlaying the river system information (Fig.3(c)). In Fig.3(d) by overlaying DEM with the buildings data, the rain fell into the ground will be no longer crossing the building as shown in Fig.3(c) any more, but the rain will go along the minimum slope to the rain grate, which is accordance with the actual case. After overlaying the factors of roads, buildings, drainage system, etc. in turn, the catchment extracted from the elaborate DEM is accordance closer with the actual rain gathering, which is mainly due to the increased information to DEM, the more information given, the better DEM reflecting earth's surface.

\subsection{Compared with $D 8$ algorithm}

Fig. 4 shows the different results between D8 algorithm and the algorithm proposed in this paper. The Watershed result given in Fig.4(a) is delineated by D8 algorithm ignoring the impact of buildings, pipe network and drainage pipes system to the rainfall runoff. In Fig.4(a), the catchment has crossed buildings and rivers, which is accordance with the actual case. The catchment delineation by the algorithm proposed in this paper is shown in Fig. 4(b), the algorithm not only considering the effect of drainage system, ditches, greenbelts, buildings on the flow direction to avoid the phenomenon of catchment area crossing the buildings, but also considering the convergence effect of rain grates and pipes.

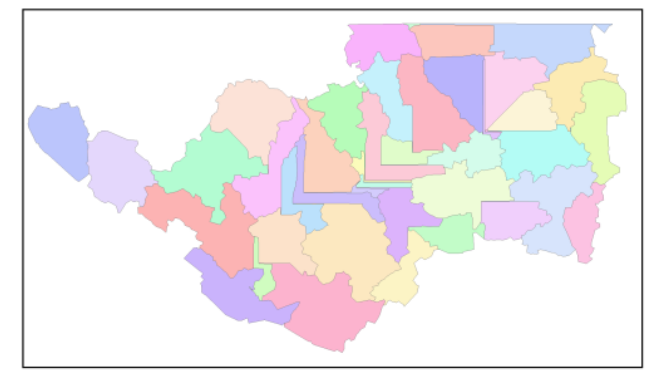

(a)

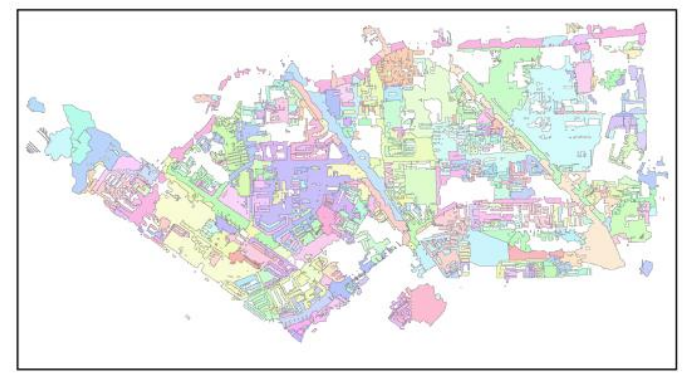

(b)

Fig. 4: Comparison of watersheds delineation based on D8 and RIDEM:(a) D8 results;(b) The results of our method in this paper.

This paper simulates the rainfall occurred at August 10, 2010 (for $4 \mathrm{~h}$ with a total rainfall $12.4 \mathrm{~mm}$ ) by the built SWMM. Fig.5 shows the comparison between the simulation results and the outlet monitoring data in the research area.

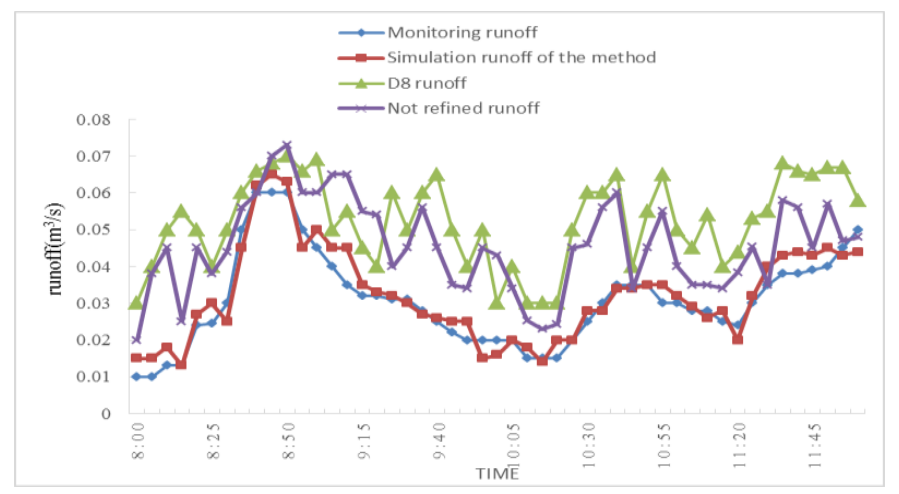

Fig. 5: Comparison between simulation results and monitoring data.

As Shown in Fig. 4, the result using D8 algorithm and unelaborate DEM is different from the monitoring data, while the simulated results using method in this paper can fit the monitoring data very well. 
Nash-Sutcliffe efficiency coefficient is used to evaluate the coincidence between simulation data curve and the actual monitoring data, as shown in Eq. 2:

$$
N S=1-\frac{\sum_{i=1}^{n}\left(Q^{s i n}-Q_{i}^{o b s}\right)^{2}}{\sum_{i=1}^{n}\left(Q^{\text {obs }}-Q^{a v}\right)}
$$

where, $N S$ as the efficiency coefficient; $Q^{\text {sim }}$ as the simulation values at moment, $\mathrm{m}^{3} / \mathrm{s} ; Q_{i}^{\text {obs }}$ as the observation values at moment, $\mathrm{m}^{3} / \mathrm{s} ; Q^{a v}$ as the average of the observation data, $\mathrm{m}^{3} / \mathrm{s}$.

The closer Nash-Sutcliffe efficiency is to 1, the higher coincidence between the simulation results and monitoring data. In the process of model validation, it is generally believed that if Nash-Sutcliffe efficiency coefficient is greater than 0.7 , the forecasting time series prediction and the monitoring time series achieve a very good match. In the experiment, Nash-Sutcliffe efficiency coefficient of the method is 0.83 , which means that it has a higher reliability and accuracy to model urban drainage using the catchment area delineated by the method proposed in the paper.

\section{Summary and Future Works}

From the above-mentioned content, the grates and drainage pipes as inlets to delineate watersheds, results are fitted well with monitoring data in SWMM.This method improved the accuracy of urban runoff models, and can be used to analysis runoff, pipe load and optimization of pipe network. Future research will follow the methodology outlined in this paper for large-scale areas and other areas. The proposed methods do not take drainage pipes flow factors into account, such as congestion leading to changes of catchment area. Based on the runoff drainage pipe network optimization can be as future research fields.

\section{Acknowledgments}

This work is financially supported by the National Natural Science Foundation of China (NO.91224008).

\section{References}

[1] L.W. Martz, J. Garbrecht. JAWRA,No.29(1993), p.901-p.908.

[2] J.Oksanen, T.Sarjakoski. International Journal of Remote Sensing, No.26(2005), p.3085-p.3102.

[3] W.T.Lin, W.C.Chou,C.Y.Lin,P.H.Huang and J.S.Tsai.Hydrol Process,No.20(2006),p.289- p.306.

[4] W.Yang, K.Hou, F.Yu, Z.Liu and T.Sun. Hydrol Earth Syst Sci Discuss ,No.7(2006),p.441-p.459.

[5] S. R.Hosseinzadeh. International Journal of Environmental Science and Development, Vol.2, No.3(2011), p.25-p.42.

[6] G. K.Anornul, A.Kabobah, and B. K. Kortatsi. International Journal of Cooperative Studies, No.1(2012), p.9-p.14.

[7] A. K. Bera,V. Singh, N. Bankar, S. S. Salunkhe and J. R. Sharma. Journal of the Indian Society of Remote Sensing,Vol.42, No.1(2014),p.187-p.199.

[8] D.R.Maidment.in:Arc Hydro GIS for water resources.ESRI Press, Redlands, CA(2002), p.203

[9] M. M. Rahman, D. S. Arya and N. K. Goel. Appl Geomat, ,No.2(2010),p.49-p.58.

[10]F.Z.KONG , X.F. RUI. Advances in Water Science,Vol.14,No.3 ( 2003),p.290-p.294.

[11] N. C. JOHN, P. V. N. KIMBERLY and S. B.GUY.Journal of Hydrology, No.332(2007),p.30- p.39.

[12]P.QUINN,K.BEVEN ,P.CHEVALLIER ,et al.Hydrological Processes, No.5(1999),p.59-p.79.

[13] R.TURCOTTE , J. P. FORTIN, A.N. ROUSSEAU,et al. Journal of Hydrology, No.240(2001), p.225-p.242.

[14] G. D.DUKE, S.W.KIENZLE, D. L.JOHNSON, et al. Journal of Spatial Hydrology,Vol.3,No.2 (2009),p.1-p.27.

[15]C.MAKSIMOVIC, D. PRODANOVIC, S, BOONYA-AROONNET, et al. Journal of Hydraulic Research, Vol.47,No.4(2009),p.512-p.523. 